\title{
A comprehensive model of vessel anchoring pressure based on machine learning to support the sustainable management of the marine environments of coastal cities
}

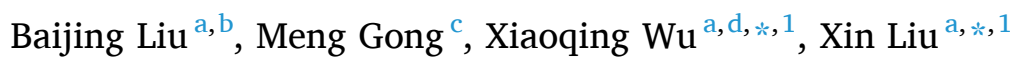 \\ a Yantai Institute of Coastal Zone Research, Chinese Academy of Sciences, Yantai, 264003, China \\ ${ }^{\mathrm{b}}$ University of Chinese Academy of Sciences, Beijing, 101400, China \\ ${ }^{\mathrm{c}}$ Provincial Geomatics Center of Jiangsu, Jiangsu, Nanjing, 210013, China \\ ${ }^{\mathrm{d}}$ Key Laboratory of Coastal Environmental Processes and Ecological Remediation, Chinese Academy of Sciences, Yantai, 264003, China
}

\section{A R T I C L E I N F O}

\section{Keywords:}

Vessel anchoring pressure

Automatic identification system

Machine learning

Illegal anchoring area

Sustainable marine management

\begin{abstract}
A B S T R A C T
The increased utilization of marine areas represents a significant challenge to the sustainable eco-environmental management of coastal cities. Machine learning, specifically the support-vector machine classification algorithm, was used to preprocess the massive Automatic identification System (AIS) dataset and extract anchoring vessels. Then, a comprehensive indicator evaluation model for anchoring pressure (CAPI) was constructed to evaluate the potential marine ecological pressure associated with anchoring vessels in the Bohai Sea. Spatial analysis was performed by geographic information system (GIS) to identify improper anchoring areas with high CAPI values. Finally, anchorage management in various coastal cities was assessed. The results showed that: (1) machine learning technology accurately identified anchoring vessels, (2) improper anchoring in the Bohai Sea is common, and (3) the management of anchoring activities is generally poor at boundaries between administrative regions. This study provides a rapid, feasible, and effective visualization method for marine environmental managers both theoretically and practically. The data mining method and CAPI model proposed here facilitate the management of vessel-related social issues in coastal cities, and they will help decision makers to quickly formulate targeted management measures to support the sustainable economic and environmental development of coastal cities.
\end{abstract}

\section{Introduction}

As countries have become increasingly aware of the potential of their marine territories, it has been recognized that proper ocean management is necessary to guarantee the sustainable economic and social development of port and coastal cities (Jasmi \& Fernando, 2018); this topic has become a crucial in recent years (Fang et al., 2021). Thoughtfully developed marine industries not only meet the needs of urban residents, but also ensure the sustainable growth of the blue economies of coastal cities (Engle \& Carole, 2016). Therefore, environmental protection and management programs focused on coastal cities should consider marine, as well as terrestrial environments. Marine environmental protection constitutes an important part of the sustainable development of coastal areas, and protection programs are critical for the sustainable economic and social development of coastal cities.

Marine transport, which is an important aspect of ocean development and utilization, has enormous economic value: marine transport accounts for approximately $80 \%$ of all transport associated with global trade, and this industry is growing at an annual average rate of over 8.5 $\%$ (Fiorini et al., 2016; Vespe et al., 2016). When marine-transport vessels are awaiting berths, quarantining, sheltering from wind, and loading or unloading at anchorage sites, they must anchor. Anchoring, which includes the deployment and retrieval of the anchor and the movement of the attached chain (Milazzo et al., 2004), has several negative effects, including noise pollution, light pollution, hydrodynamic interaction, substrate loss, oil pollution, and biological invasion. Because vessels primarily anchor in shallow offshore waters, the marine habitats of these waters are unavoidably mechanically disturbed, directly and indirectly damaging the marine ecosystem (Costanza et al.,

\footnotetext{
* Corresponding authors at: Yantai Institute of Coastal Zone Research, Chinese Academy of Sciences, Yantai, 264003, China.

E-mail addresses: xiaoqingwuyic@163.com (X. Wu), xliu@yic.ac.cn (X. Liu).

1 These authors contribute equally to this work.
} 
1997; Deter et al., 2017; Graham et al., 2015). This type of damage can be compared to digging up roads and farmlands. Damages are even more severe when vessels anchor outside government-prescribed anchorages. Thus, improper vessel anchoring substantially restricts the sustainable development of the marine economies of coastal cities, negatively affecting industries such as marine transportation, marine fisheries, and seawater utilization (Manna et al., 2015; Rogers \& Garrison, 2001). The positioning and quantification of vessel anchoring pressure are therefore important aspects of marine ecological protection. Consideration of these factors is critical to ensure human and vessel safety, as well as the sustainable management of the marine environment (Fang et al., 2021; Hendriks et al., 2013).

Over the last few decades, social and regulatory bodies have primarily relied on direct observations (Abadie et al., 2016; Francour et al., 1999) and aerial photography (Holon et al., 2015) to evaluate anchoring pressure. However, these methods are more applicable to small-scale assessments focused on the physical damage caused by the deployment and retrieval of anchors and the movement of connecting rods (Lester et al., 2016); other sources of pollution or threats to the natural ecosystem posed by the anchoring of the vessel are thus ignored. In addition, direct observations and aerial photographs frequently fail to precisely identify vessel type and anchoring time, necessitating extensive and time-consuming cross-checking using high-frequency continuous monitoring. This process is unsuitable for large-scale marine management (Bremer and Glavovic, 2013; Willsteed et al., 2018).

Marine management authorities play a key role in protecting society from the harmful effects of improper anchoring. Although some previous marine environmental management studies have focused on anchoring operations, the increased ecosystem pressure associated with the anchoring process should be further investigated. Efficient and accurate management of anchored vessels can help vessels to follow the regulations of the International Maritime Organization (IMO) regarding anchoring, thereby promoting the coordinated sustainable economic, cultural, and environmental development of coastal cities. Therefore, it is necessary to develop an efficient and accurate evaluation framework to provide long-term support for decision-making with respect to wateruse management and marine ecological protection (Giakoumi et al., 2015; La Manna et al., 2015; Venturini et al., 2016).

The rapid development and wide application of artificial intelligence and big data has led environmental management researchers to consider artificial intelligence based on big data (Shafiee et al., 2017). For example, meteorological and environmental, disaster, and geographical data have frequently been applied in assessments of marine ecological protection and safety, providing strong support for the sustainable development of the blue economy (Milojevic-Dupont \& Creutzig, 2021). The automatic identification system (AIS), which is gradually becoming more well known, has been widely used in studies of environmental protection and sustainable development (Robards et al., 2016). AIS vessel data are used by the IMO to support navigation and communication (Mandal et al., 2018). These data provide a vital basic guarantee for maritime management departments to ensure vessel traffic safety, protect the marine environment, and realize green shipping (Johansson et al., 2017). AIS data contain much valuable information, including vessel name, size, tonnage, speed, location, and navigation status. In contrast to other vessel monitoring methods, the AIS is free from the influence of weather, sea conditions, and obstacles; AIS also supports the regular, automatic, and autonomous exchange of vessel information, making it an important tool for monitoring vessel transport safety and managing risk (Liu, Shi et al., 2019). The International Convention for Safety of Life at Sea (SOLAS Convention) stated that from 1 July 2003, vessels manufactured before 1 July 2002 should be configured with AIS equipment (Mazzarella et al., 2017). The compulsory installation of an AIS allows vessel information to be used to avoid ship collisions (Liu, Wu et al., 2019), construct decision-making systems to minimize oil-spill risk (Eide et al., 2007), and identify fishing areas (Kim and Lee, 2020; Piet et al., 2006; Russo et al., 2013). However, because AIS data are huge and complex, target extraction and quality control are difficult, limiting the utility of these data. Therefore, it is imperative to devise a framework for AIS data sorting and mining. In this study, we used machine learning to explore and improve the applicability of AIS big data to the management of anchored vessels in coastal cities based on typical case study.

Taking a case study of Bohai Sea,the information about anchoring vessels were extracted from the AIS big data using machine learning. Then, an anchorage analysis model was established to evaluate the pressure exerted by vessel anchoring on the marine environment. In conjunction with geological information about the Bohai Sea, we used AIS data to quantify and analyze anchoring pressure from multiple perspectives, including the number of anchoring vessels, the scope of affected areas, and the vessel attributes, in order to reveal the temporalspatial distributions of ecological environment pressure and the management levels of vessels anchoring in the Bohai Sea. We also provided policy suggestions for anchorage delineation and the sustainable management of the marine environment, exploring the theoretical analysis and application of our results in a sustainable coastal society.

\section{Materials and methods}

\subsection{Study area}

The study area $\left(37^{\circ}-41^{\circ} \mathrm{N}\right.$ and $\left.117^{\circ}-122^{\circ} \mathrm{E}\right)$ included the Bohai Sea and the surrounding Yellow Sea (Fig. 1). It had $3784 \mathrm{~km}$ of coastline, and a total sea area of 77,284 square kilometers. There are more than 20 ports along this coastline. Because the Bohai Sea is shallow, with low wind and water velocities, it is an ideal anchoring location for vessels arriving in northern China. Indeed, many ships anchor throughout the Bohai Sea. Therefore, the Bohai Sea represents an ideal area for our study.

The Bohai Sea is not only a crucial component of China's offshore fishery economy,but is also an important channel for China's marine economy and trade (Guo et al., 2019). Vessels not anchored within a specified range increase ecological pressure and threaten the safety of marine transportation in the Bohai Sea, challenging both the sustainable development of the marine economy and the established environmental protection measures. Therefore, the evaluation of the ecological pressures associated with vessels anchoring within the Bohai Sea allows us to demonstrate the utility of the proposed method for guiding the management of marine-vessel anchoring.

\subsection{Data preprocessing}

In this study, AIS data purchased from Shipxy (http://www.shipxy. $\mathrm{com} /$ ) were used to characterize vessels. The sediment data were obtained from the Atlas of China's Offshore Ocean-Submarine Topography, compiled by the State Oceanic Administration and the Chinese Academy of Sciences in 2017. Due to the large size of the dataset, as well as the characteristic daily, monthly, and seasonal changes in vessel activities in the Bohai Sea, we used the uniform sampling method to preprocess the AIS data for the Bohai Sea in 2018. In this way, we ensured that the postsampling data were as representative as possible. Specifically, the data were sampled daily every three days from January 1 , and the data for the first minute of each hour of each day were selected. Thus, on each day vessel distributions over a total of 24 min were sampled. We obtained the missing data for each vessel (length, type, and deadweight tonnage) using vessel name and Maritime Mobile Service Identify (MMSI) number. All vessel data, including vessel location (latitude and longitude) were imported into Geographic Information System (GIS), and the distribution of the anchored vessels was then analyzed using machine learning.

When a vessel is anchoring, its operating state in the AIS data is marked as "anchor". However, data irregularities may arise due to equipment failure. Alternatively, when the anchoring vessels start to 

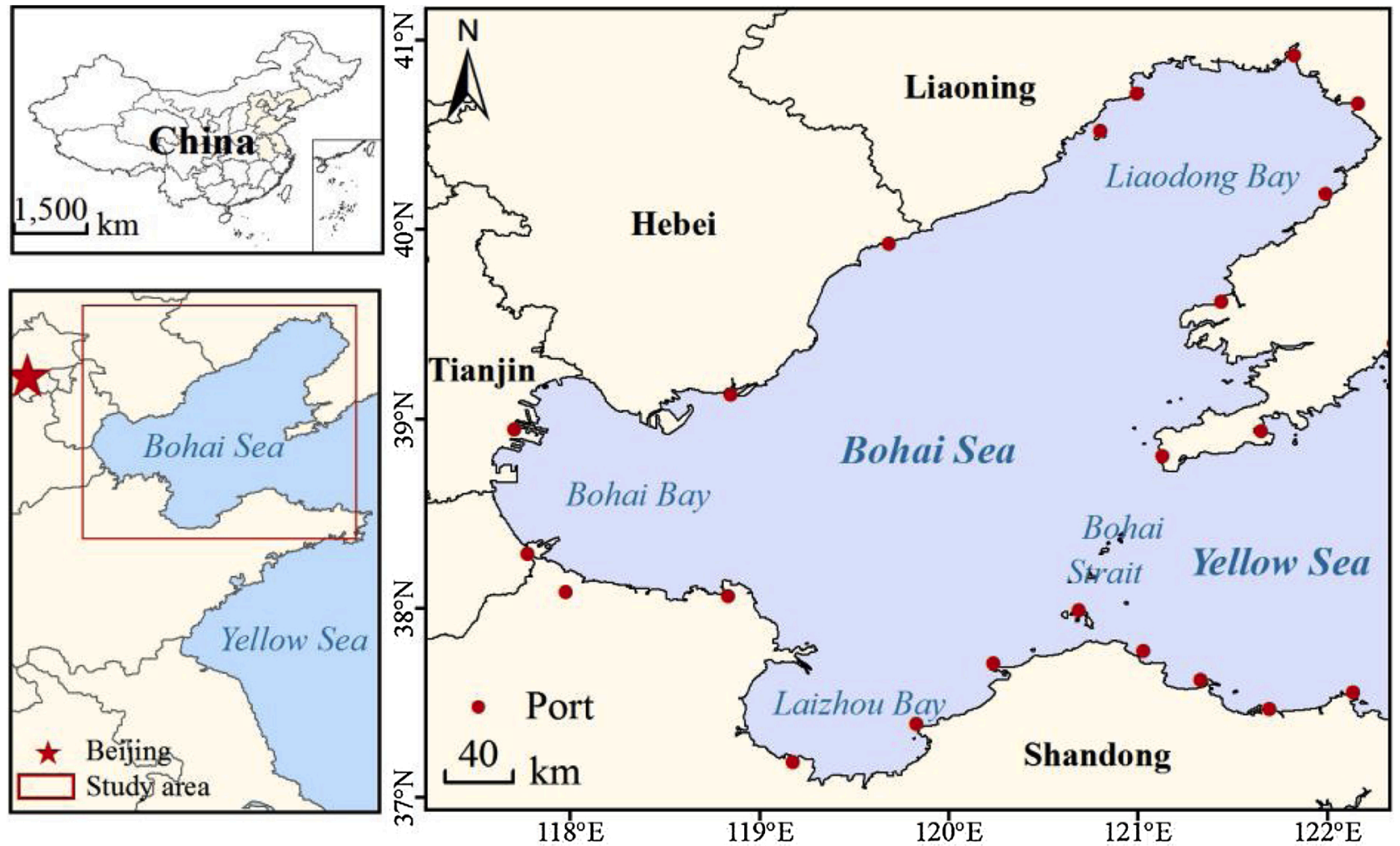

Fig. 1. The geographical location of the study area. sailing or berthing, the operators may forget to change the AIS state, which leads to the fact that some of the vessels in the AIS data marked as "anchor" contain the vessel position information that are not anchoring. To address these potential issues, machine learning technology was used to preprocess the raw AIS data (Fig. 2). Specifically, we performed supervised machine learning on the AIS data using the support-vector machine classification algorithm, with vessel speed as the characteristic attribute in combination with the distribution of anchorages in the Bohai Sea. Previous studies have suggested that the support-vector

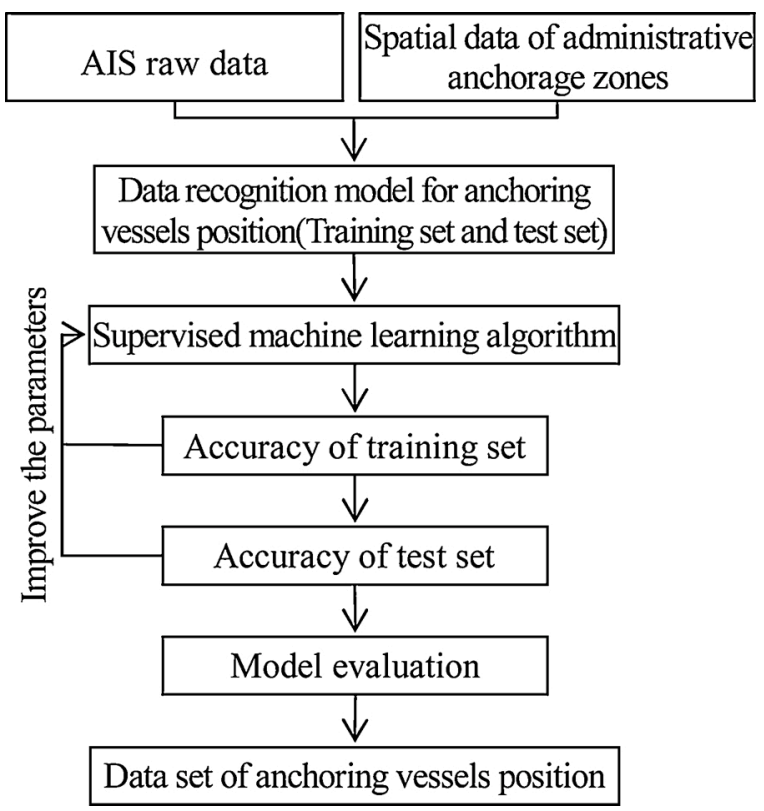

Fig. 2. Automatic identification System (AIS) data processing flow for the supervised machine learning method. machine algorithm more efficiently and accurately solves the dichotomy problem as compared to previous methods that manually preprocessed the AIS data (Collobert \& Bengio, 2001). The database used in the study contained a total of 246,429 anchored vessel positions with speeds ranging from 0 to 0.87 knots. These positions were selected from a total of 8,623,953 vessel positions in the AIS data for 2018. These numbers were roughly consistent with previous identifications of anchoring vessels (Deter et al., 2017).

\subsection{Establishing the evaluation index system}

In this study, we established an indicator system based on the nature of the vessel anchored in order to evaluate the associated pressure on the marine environment. The environmental pressures were subsequently divided into three types: physical, chemical, and biological.

The Convention on the International Regulations for Preventing Collisions at Sea clearly stipulates the sound and light signals that are required for vessels of different sizes and types when anchored. These lights and sounds directly produce noise and light pollution. The deployment, shaking, and retrieval of anchor chains, cables, or ropes disrupt the dynamic seawater environment, causing local hydrodynamic disturbances. The actual anchoring damages the substrate. Although the movement of anchored vessels is relatively limited compared to that of vessels under sail, collisions and oil spills are still possible. Moreover,in order to reduce the waiting time for berthing, some anchored vessels discharge ballast water in advance at the anchorage site, risking fuel leakage and/or the introduction of non-native species. Therefore, oil pollution and biological invasion must also be taken into consideration. Based on these factors, we identified six distinct types of pressure: noise pollution, light pollution, hydrodynamic interaction, substrate loss, oil pollution, and biological invasion (Table 1 ).

\subsection{Indicator assignment}

The following principles were primarily used when determining the 
Table 1

Glossary of terms and definitions.

\begin{tabular}{|c|c|c|}
\hline $\begin{array}{l}\text { Primary } \\
\text { index }\end{array}$ & Secondary index & Definition \\
\hline & Noise pollution & $\begin{array}{l}\text { The negative impact of noise produced by } \\
\text { auxiliary machinery, hull vibration, and } \\
\text { sound signal equipment on marine organisms } \\
\text { when vessel is anchoring. }\end{array}$ \\
\hline & Light pollution & $\begin{array}{l}\text { The negative influence of vessel formation } \\
\text { lights and signal lights on marine organisms. }\end{array}$ \\
\hline Physical & $\begin{array}{l}\text { Hydrodynamic } \\
\text { interaction }\end{array}$ & $\begin{array}{l}\text { Changes in water flow (speed or direction) } \\
\text { and waves (size, number, or period) caused } \\
\text { by vessel anchoring. This index was limited to } \\
\text { the direct effects on the water body, such as } \\
\text { changing the sedimentation rate, affecting the } \\
\text { growth of aquatic plants, and interfering with } \\
\text { the natural swimming patterns of marine } \\
\text { animals. Indirect effects, such as seabed/ } \\
\text { coastal erosion caused by hydrodynamic } \\
\text { changes, were not considered. }\end{array}$ \\
\hline & Substrate loss & $\begin{array}{l}\text { Physical damage to the seabed caused by } \\
\text { vessel anchoring. This includes the damage } \\
\text { caused by the dragging of anchor chains and } \\
\text { the bottom contact of the anchor hook. }\end{array}$ \\
\hline Chemical & Oil pollution & $\begin{array}{l}\text { Oil pollution caused by oily sewage discharge } \\
\text { and/or accidental oil spills during ship } \\
\text { collisions/stranding. Oil pollution hinders the } \\
\text { photosynthesis of marine plants; affects } \\
\text { animal activities, feeding, reproduction, and } \\
\text { growth; changes fish migration routes; and } \\
\text { contaminates seafood. }\end{array}$ \\
\hline Biological & Biological invasion & $\begin{array}{l}\text { Any organism that is carried to a new } \\
\text { environment in ballast water and causes harm } \\
\text { to the local ecosystem. }\end{array}$ \\
\hline
\end{tabular}

assignment standards for the evaluation indicators: (1) scientificity: the assignment standard should be science-based (i.e., based on existing rules and regulations or existing references); (2) operability: the indicators should have clear meanings, and the data should be easy to obtain, calculate, compare, and analyze, thus facilitating management and operation, as well as allowing the integration of theory and practice; (3) hierarchy: due to the complexity of the vessels (type, size, and deadweight tonnage), previous research results and actual conditions should be considered in the determination of the standard,and uniform assignment should be avoided; and (4) combining qualitative description and quantitative analysis: qualitative questions should be quantified as best as possible,so that they can be processed by mathematical models to achieve an objective, rational, and comprehensive evaluation.

To ensure the accuracy of the evaluation results, the indicators were first scored. All evaluation indicators were standardized to prevent the differing orders of magnitude among indicators from influencing the comparisons. The grading standards in this study were mainly based on relevant international, national, industrial, or local standards (IMO, 2004; IMO, 2007; MOT, 2014; MOT, 2017). Division standards and values were set for each indicator (Table 2). Specifically, noise pollution and light pollution were determined based on the International Regulations for Preventing Collisions at Sea, hydrodynamic interaction was determined based on China's Overall Design Code of for Sea Ports, substrate data was obtained from the vectorization of the Atlas of the Comprehensive Survey and results of China's Offshore Oceans-Submarine Special Evaluation, oil pollution was determined based on the Technical Guidelines on Environmental Risk Assessment of Oil Spills at Waters, biological invasion was determined based on the International Convention for the Control and Management of Ships Ballast Water and Sediments.

After assigning indicators to each anchoring vessel in accordance with our standards (Table 2 ), the study area was gridded ( $1 \mathrm{~km} \times 1 \mathrm{~km})$ to facilitate subsequent spatial analysis. The impact indicators of all vessels within each grid square were summed, and the result was standardized to a value of $0-1$ using Eq. (1). Because the number of vessels per grid square varied tremendously, vessel numbers were subjected to logarithmic transformation to standardize extreme values.

$X^{*}=\frac{\lg x-(\lg x) \min }{(\lg x) \max -(\lg x) \min }$,

Where $X^{*}$ and $x$ are the standardized value and the actual value, respectively, and $(\lg X)_{\max }$ and $(\lg X)_{\min }$ represent the maximum and minimum, respectively, of the logarithmic transformation of all indicators on which the statistical analysis was performed in each grid unit.

\subsection{Comprehensive anchoring pressure index (CAPI) model}

Following previous studies (Liu et al., 2021), we proposed a comprehensive anchoring pressure index (CAPI) model using the evaluation index system established above. The basic aim of this model was to calculate the weighted standardized indicators. The CAPI index was set to $0-1$,where greater values reflect greater anchoring-associated effects. The model is shown in Eq. (2).

$C A P I=\sum(P m \times W m+C n \times W n+B u \times W u)$

Where $P_{m}, C_{n}$, and $B_{u}$ are the standardized values of the $m^{\text {th }}, n^{\text {th }}$, and $u^{\text {th }}$ physical, chemical, and biological impact indicators, respectively. $W_{m}$, $W_{n}$, and $W_{u}$ denote the weights of each indicator. The grading criteria for each indicator were based on national or international standards. Thus, indicators with the same weight were considered equal so as to avoid discrepancies caused by subjective judgments.

\section{Result}

\subsection{Identification of anchoring vessel positions}

Before assessing vessel anchoring pressure, we first analyzed vessel anchoring statistics in the Bohai Sea to better clarify the need for such an assessment. We found that $61.86 \%$ of all vessels (mainly cargo ships) were anchored outside the government-designated anchorage sites in the Bohai Sea (Fig. 3). Thus, improper anchoring is a serious problem in the Bohai Sea, and an effective approach is urgently needed to identify problematic areas in order to avoid unexpected damage to the marine

Table 2

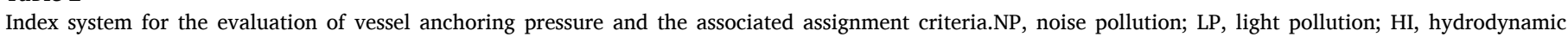
interaction; SL, substrate loss; OP, oil pollution; BI, biological invasion; DWT, deadweight tonnage.

\begin{tabular}{|c|c|c|c|c|c|c|c|c|}
\hline & \multirow{2}{*}{ Index } & \multirow{2}{*}{ Vessel type } & \multirow{2}{*}{ Unit } & \multicolumn{5}{|c|}{ Grading criteria } \\
\hline & & & & 1 & 0.8 & 0.6 & 0.4 & 0.2 \\
\hline \multirow{4}{*}{ Physical } & NP & All & length (m) & $x \geq 150$ & $100 \leq x<150$ & $50 \leq x<100$ & $12 \leq x<50$ & $x<12$ \\
\hline & LP & All & length (m) & $x \geq 100$ & $50 \leq x<100$ & $12 \leq x<50$ & $7 \leq x<12$ & $x<7$ \\
\hline & HI & All & length (m) & $x \geq 25$ & $15 \leq x<25$ & $8 \leq x<15$ & $4 \leq x<8$ & $x<4$ \\
\hline & SL & All & - & Clay & Clayey silt & Silt & Sand & Gravel \\
\hline \multirow{2}{*}{ Chemical } & \multirow{2}{*}{$\mathrm{OP}$} & Oil tanker & DWT (t) & $x \geq 80,000$ & $30,000 \leq x<80,000$ & $5000 \leq x<30,000$ & $1000 \leq x<5000$ & $x<1000$ \\
\hline & & Cargo ship & DWT (t) & $x \geq 50,000$ & $30,000 \leq x<50,000$ & $10,000 \leq x<30,000$ & $5000 \leq x<10,000$ & $x<5000$ \\
\hline Biological & BI & Oil tanker, cargo ship & DWT (t) & $x \geq 50,000$ & $15,000 \leq x<50,000$ & $5000 \leq x<15,000$ & $1500 \leq x<5000$ & $x<1500$ \\
\hline
\end{tabular}




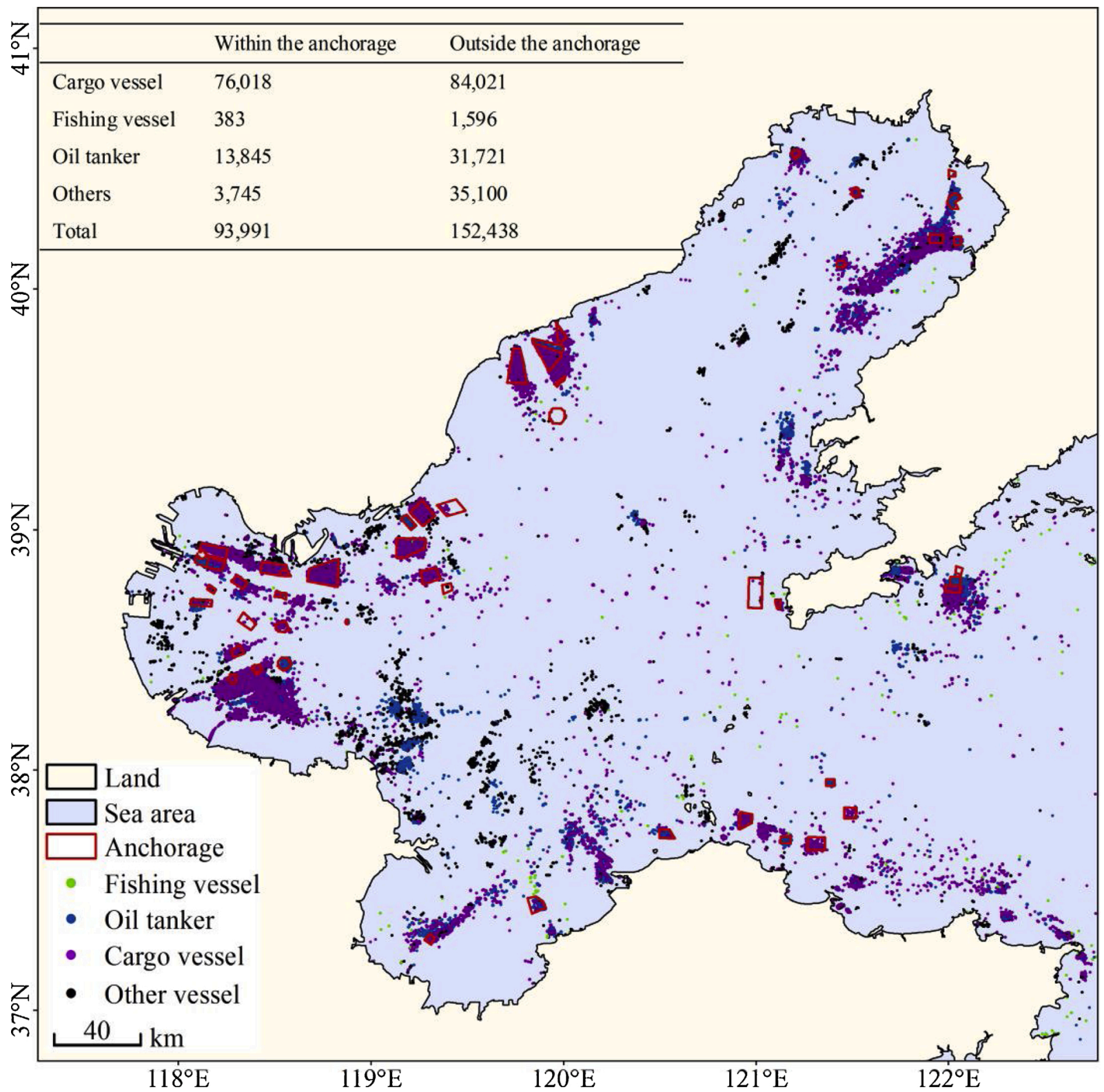

Fig. 3. Location of anchoring vessels inside and outside official anchorage sites in the Bohai Sea.

ecological environment and to support sustainable marine and coastal development.

\subsection{Spatial analysis of CAPI}

The CAPI distribution in the Bohai Sea was obtained as described above using the natural break point method in GIS. The overall CAPI distribution pattern in the Bohai Sea was similar to that of anchoring vessel positions, with high index values in areas where the anchoring vessels were closely distributed (Fig. 4). This was consistent with previous studies, which have shown that dense pockets of activity have more significant effects on the environment, even leading to habitat loss (Scanes, 2018) Compared with the distribution of vessel density, the scope of CAPI influence had more obvious boundaries. This is because the evaluation model de-emphasized locations with low vessel densities and small vessels to more clearly highlight the areas that should be prioritized for supervision.

Spatial distribution analysis clearly showed that the areas with high CAPI values were primarily located offshore, especially in the gulf, which was consistent with typical vessel anchoring patterns. Specifically, $75.69 \%$ of the high CAPI values were recorded at water depths of 0-20 m, consistent with characteristic that vessels generally tend to anchor in shallow waters, and $56.74 \%$ of the high CAPI-value areas were recorded in Bohai Bay. Many of these vessels were cargo vessels, presumably due to the large freight industries of the cities along the Bohai Bay coast. The high CAPI-value areas in Liaodong Bay and Laizhou Bay were concentrated along a relatively small strip of shipping lanes. This was because cargo vessels must queue to enter/depart some of the freight ports in Liaodong Bay and Laizhou Bay. Our results recovered almost no vessel anchoring pressure in the channels of the central Bohai Sea and the Bohai Strait, which indirectly verifies the accuracy and rationality of our data extraction method.

\subsection{Temporal analysis of CAPI}

During the study period (2018), the number of anchored vessels was highest in August and September (Fig. 5). This may be because cargo and passenger traffic through ports along the Bohai Sea increased notably in 

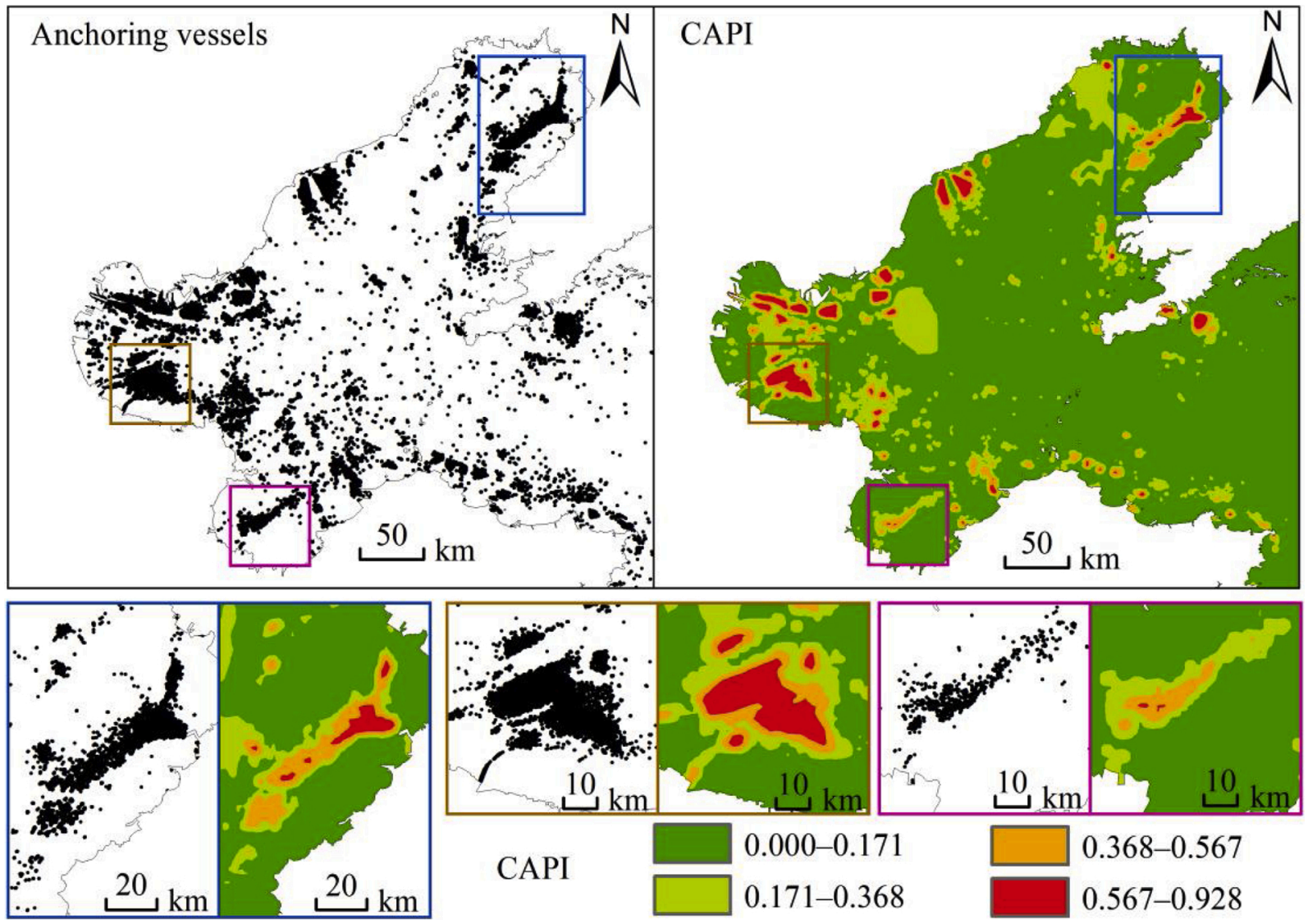

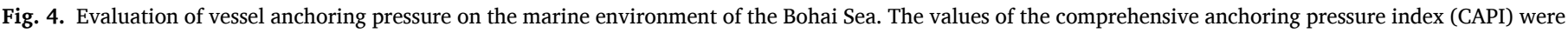
classified according to the natural break point method.

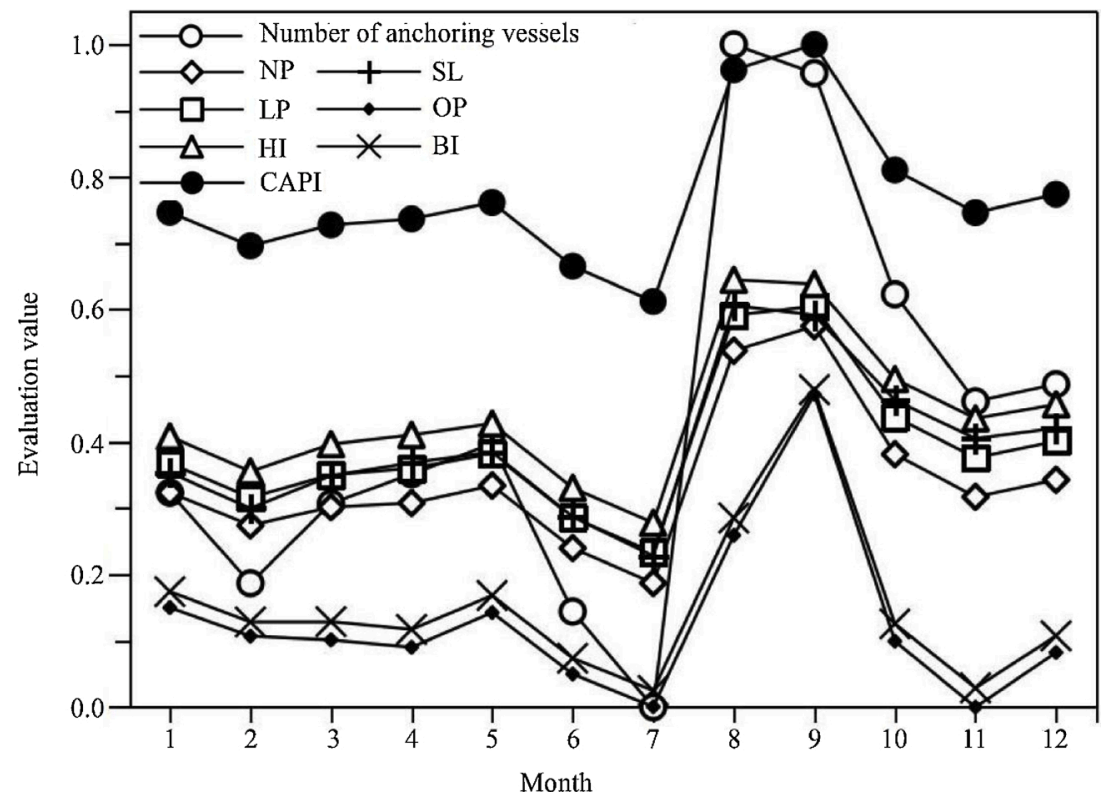

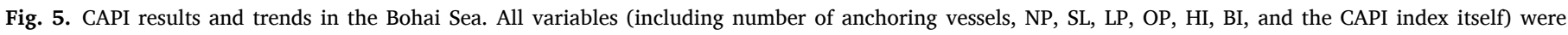

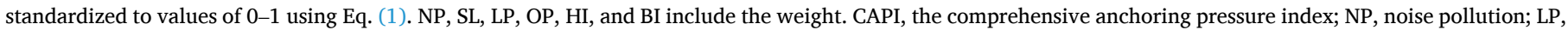
light pollution; HI, hydrodynamic interaction; SL, substrate loss; OP, oil pollution; BI, biological invasion.

2018: $19.85 \%$ of all cargo and $34.87 \%$ of all passengers in China in 2018 passed through the Bohai Sea (http://www.mot.gov.cn/tongjishuj u/gangkouhuowulvkettl/index_1.html). Following a slight decline, the CAPI index increased sharply between May and August, reflecting the improper anchoring of cargo vessels following the commencement of the fishing season. Conversely, the CAPI index dropped sharply between September and December, coinciding with the end of the fishing season. In order to avoid accidental collisions, the improper anchoring of cargo 
vessels and oil tankers must be minimized. The estimation of all subindices showed that hydrodynamic interactions (HI) were the largest contributor to CAPI, followed by light pollution (LP) and substrate loss (SL), whereas oil pollution (OP) was the smallest contributor. Although CAPI values fluctuated, similarity to monthly changes in the numbers of anchoring vessels, there were still obvious differences among vessels number and CAPI value, emphasizing the necessity of including vessel type, size, and deadweight tonnage in the CAPI evaluation.

\subsection{Analysis of anchorage legitimacy}

Marine administrative authorities have designated several fixed polygonal zones for vessel anchoring in the Bohai Sea. Because vessels are connected to the water column via a chain when anchored, there is theoretically a small degree of uncertainty in the observed location of the vessel. Generally, anchor chains do not exceed a few hundred meters in length (Zou et al., 2012). Therefore, we surrounded each government-designated anchorage zone by a $1 \mathrm{~km}$ buffer on all sides and considered these larger areas legitimate anchoring zones. The remaining sea areas were defined as illegitimate anchoring zones. Furthermore, in areas with low CAPI values, the impact of vessel anchoring on the marine ecological environment was relatively small. Therefore, we focused on areas with high CAPI values $(0.567-0.928)$. The above-mentioned layers were spatially superimposed using GIS to analyze the legality of anchoring activities (Fig. 6).

Our results showed that the management of anchoring in the Bohai Sea is relatively poor: only $48.11 \%$ of areas with high CAPI values coincide with the anchorage zones designated by the government. The remaining $51.89 \%$ of the anchorages are outside designated anchoring zones, potentially harming biological resources and negatively impacting transportation safety in the Bohai Sea.

To facilitate management and clarify responsibilities, the China Maritime Safety Administration divided the study area into 8 administrative regions across14 coastal cities (Wang et al., 2018). Some neighboring cities were responsible for relatively small areas, and these areas were thus merged. The distribution and coding of the administrative regions are shown in Fig. 7. In this study, the GIS quantitative classification function was used to represent mean CAPI values and the rate of improper anchorage activity as circles of different color and size, respectively. In this way, we visualized the spatial distribution of anchorage management areas in each administrative region.

Statistical analyses showed that, across all administrative regions in the Bohai Sea, areas B and C had the highest mean CAPI values, while areas $\mathrm{E}$ and $\mathrm{H}$ had the lowest. This indicated that anchoring pressure is mainly concentrated in shallow waters. These results, in conjunction with those shown in Fig. 6, suggested that improper anchoring activities

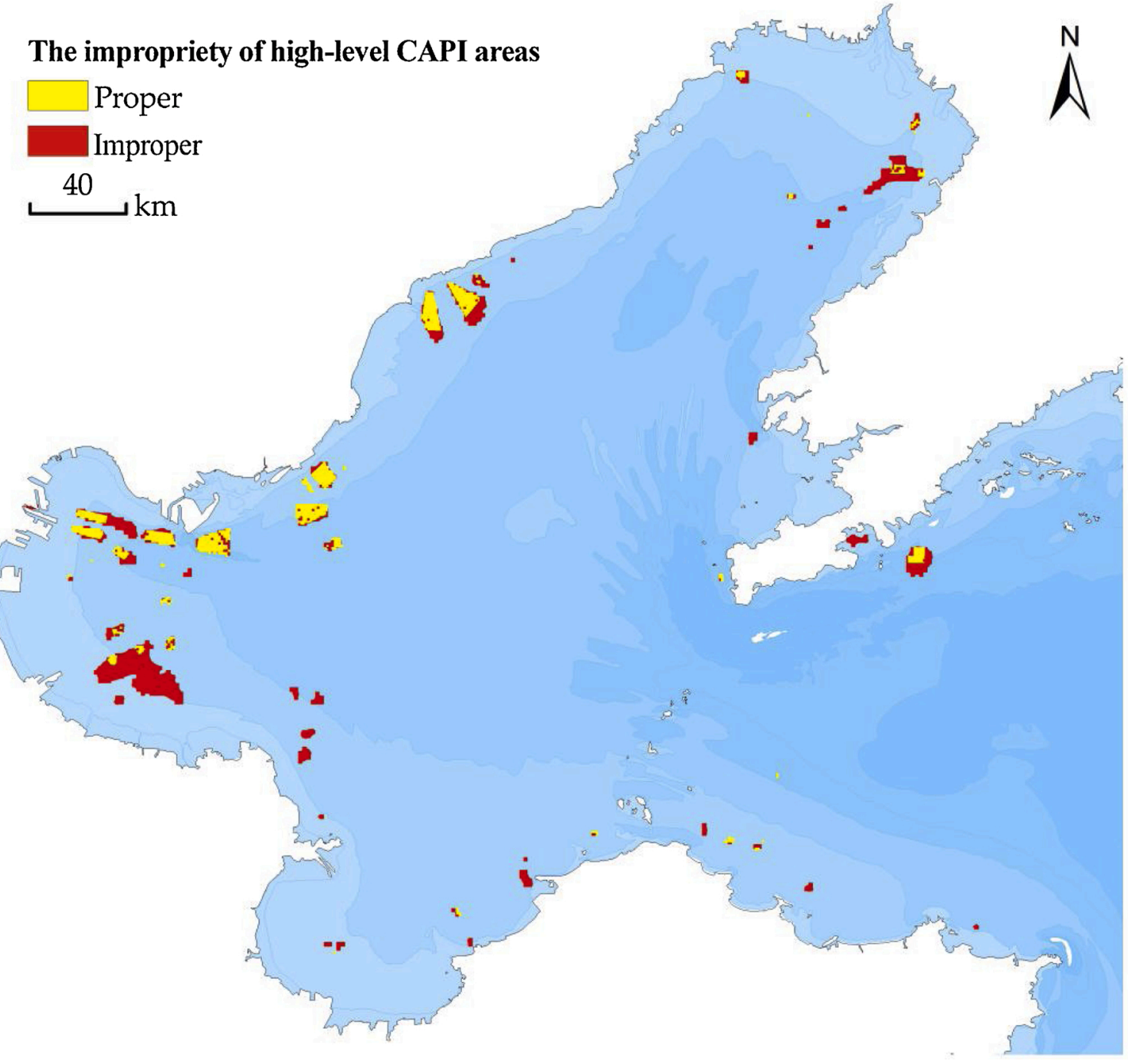

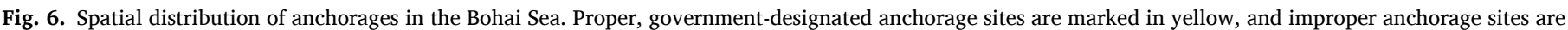
marked in red. Only areas with high CAPI values are shown. 


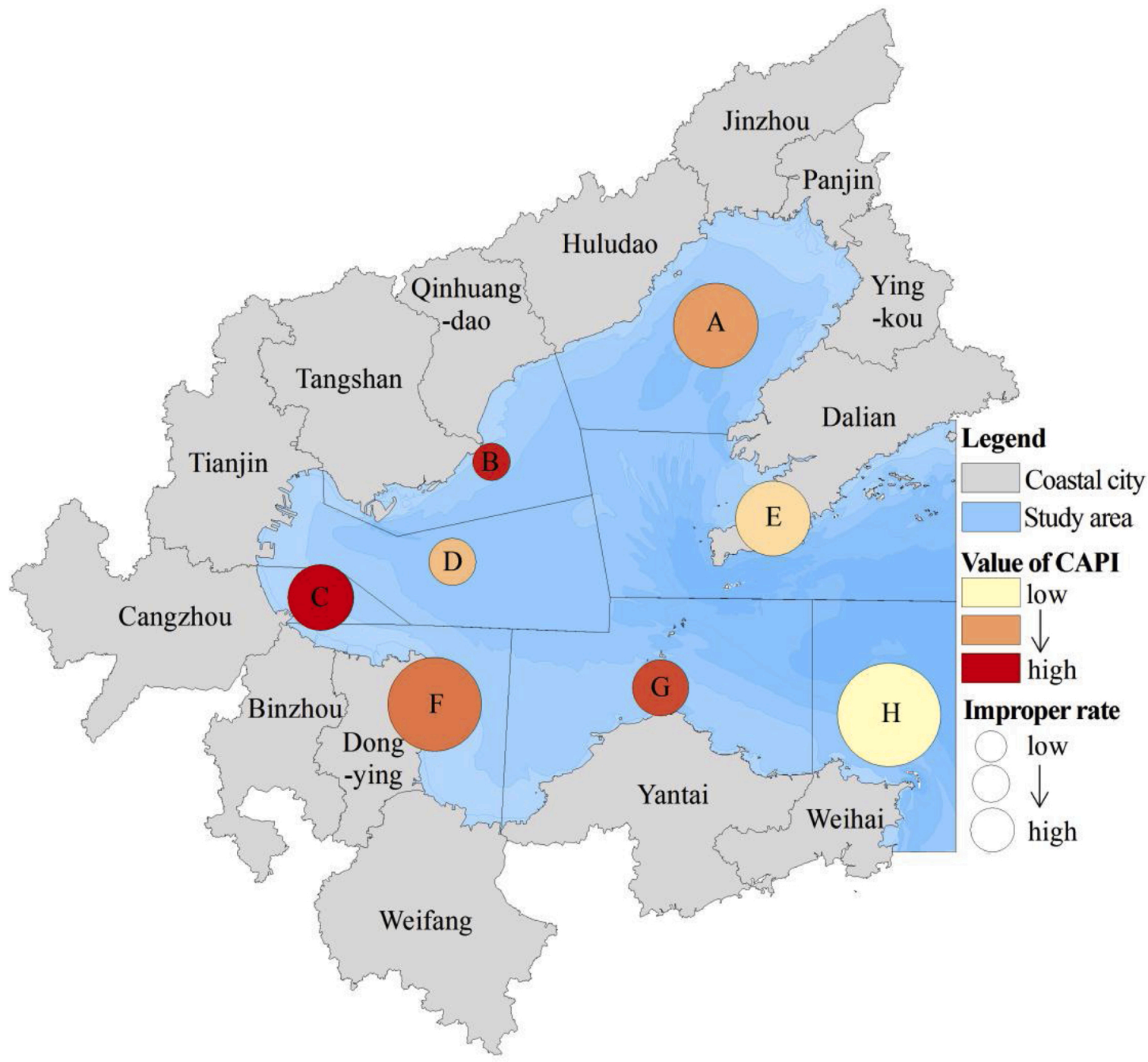

Fig. 7. Distribution of anchorage management areas across administrative regions in the Bohai Sea.

are more common at the borders between administrative regions. This may be because borders between marine administrative areas are less clear than those on land, and administers are thus less likely to enforce regulations along their marine borders. Analysis of the management of anchorage activities in different areas showed that the improper anchoring rates in areas $\mathrm{A}, \mathrm{F}$, and $\mathrm{H}$ were relatively high, suggesting that large administrative regions are more prone to insufficient management and the associated deleterious effects.

\section{Discussion}

The method proposed here used machine learning to identify anchoring vessels for the first time. This method may help to improve the efficiency with which social issues related to vessel activities are managed by coastal cities. Our evaluation of the marine ecological pressure associated with vessel anchoring in the Bohai Sea showed that the CAPI model was scientifically feasible, with the results conforming to a partial normal distribution of geostatistical data (Fig. 8). Compared with other studies, the CAPI model, which combines machine learning and GIS data, had improved universality and better spatial efficacy. This may be because the data identification method was based on artificial intelligence and used a more comprehensive indicator system. For example, multiple parameters, including the number of anchoring vessels, as well as vessel type, length, and deadweight, were included in our

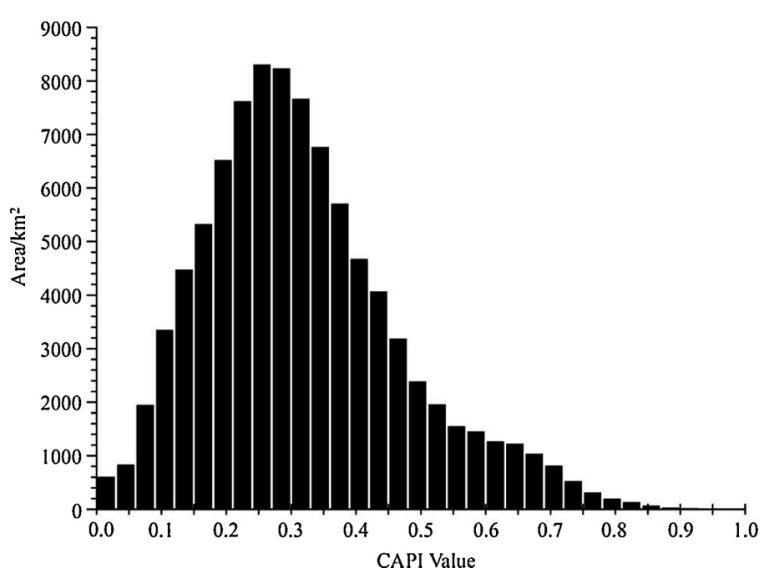

Fig. 8. Geostatistical analysis results showing the normal distribution of CAPI values.

evaluation indicators. In contrast, Deter et al. (2017) only considered the number and duration of anchoring vessels when calculating the pressure of vessel anchoring on the coastal seabed. Compared with previous studies, which monitored the temporal-spatial distributions of anchoring vessels to assess the management of anchorage activities 
(Deter et al., 2017; Francour et al., 1999; Hendriks et al., 2013), the anchoring-associated ecological pressure metrics obtained using the CAPI model may better reflect field conditions, as this indicator system takes international, national, or industry standards and regulations into consideration. In addition, the type, length, and deadweight tonnage of each vessel are included in the evaluation system. The use of these multiple aspects of anchorage activities ensured that the ecological pressures associated with vessel anchorages were more comprehensively identified, and the locations requiring priority targeting were more accurately identified.

To help decision-makers quickly judge and identify the management areas with high risks of vessel activity pressure, the indicators used in this study were based on existing rules and regulations, and the AIS vessel data were used for calculation and assignment. The preprocessing of the massive AIS dataset using machine learning techniques was more efficient, accurate, and rapid than manually monitoring the data.

The limitations of this study are mainly associated with the accuracy and penetration of the AIS data. AIS equipment failure or mistakes in AIS operation, although unlikely, may have reduced data accuracy. In addition, some vessels may not have AIS equipment installed. China follows International Maritime Organization (IMO) regulations, which state that international vessels of 300 gross tonnage and above, noninternational vessels of 200 gross tonnage and above, fishing vessels with a total length of more than $15 \mathrm{~m}$, and all passenger vessels must install AIS equipment (Mazzarella et al., 2017). Although other ships typically install AIS for safety reasons, some vessels, such as small fishing ships, may not. As global awareness of maritime navigation safety has increased, the proportion of ships carrying AIS equipment has increased (Mccauley et al., 2016). Some countries, such as Mauritius and Ecuador, require all vessels to be equipped with AIS equipment (Natale et al., 2015). It is believed that other countries will gradually require the installation of AIS on all vessels. Therefore, despite its limitations, AIS remains an important tool used by marine administrative authorities to ensure vessel transportation safety, improve shipping efficiency, and protect the water environment. AIS is thus the most efficient and accurate source of vessel information. In addition, it was extremely difficult to disentangle the specific relationships among multiple types of pressure via field testing (i.e., superposition, synergy, or antagonism) (Brown et al., 2014; Crain et al., 2008; Darling and Isabelle, 2008). To circumvent this difficulty, international and national standards were used as references during the construction of the research indicators, and the equal weight method was adopted to superimpose and calculate the indicators.

This study emphasized that future work in this area must be multidisciplinary, requiring the participation of experts from multiple fields to develop automatic open-source assessment tools to improve the efficiency of CAPI evaluation. Only in this way can the effects of anchoring on the marine ecological environment be efficiently evaluated. The development of such a tool would improve the convenience and reproducibility of the evaluation method, thus supporting government management of regional sea areas and enhancing marine ecological protection.

\section{Conclusion}

In this paper, we used the support vector machine classification algorithm to extract anchoring vessels from the massive AIS dataset, constructed an index system, and we proposed a comprehensive model for the evaluation of the marine ecological pressure associated with vessel anchoring using the Bohai Sea as a case study. The results demonstrated the effectiveness of the proposed method, as well as its theoretical and practical feasibility. This study had four main conclusions. First, compared with the time-consuming and inaccurate manual method of data processing based on experience, machine learning techniques identify anchoring vessels more quickly and accurately. Second, the anchoring pressure in the Bohai Sea is generally high, particularly in offshore areas. CAPI increases significantly from July to September, with the HI index being the largest contributor. Third, a concerning level of improper anchoring was identified in the Bohai Sea, with $51.89 \%$ of all anchorage activities occurring outside of government-designated areas. Fourth, the management of anchorage activities in the Bohai Sea is generally poor, especially at the borders between administrative areas.

This study provided an effective framework for the evaluation of the marine ecological pressures associated with vessel anchoring. The methods used to select and assign standards within the index system are relatively universal and reproducible, allowing the CAPI model to be adjusted based on industry requirements and data availability in the area to be assessed. Thus, this method provides theoretical support for marine vessel management and ecological environmental protection in coastal cities. Our model will help decision-makers to rapidly formulate objective management measures, supporting the sustainable economic and environmental development of coastal cities.

\section{Declaration of Competing Interest}

All authors declare that they have no known competing financial interests or personal relationships that could have appeared to influence the work reported in this manuscript.

\section{Acknowledgments}

We thank the editors and reviewers for their detailed and constructive comments to improve the quality of the manuscript. This work was supported by the National Key R\&D Program of China (grant number 2019YFD0900705), and Shandong Provincial Natural Science Foundation (grant number ZR2020MD014).

\section{References}

Abadie, A., Lejeune, P., Pergent, G., \& Gobert, S. (2016). From mechanical to chemical impact of anchoring in seagrasses: The premises of anthropogenic patch generation in Posidonia oceanica meadows. Marine Pollution Bulletin, 109(1), 61-71. https:// doi.org/10.1016/j.marpolbul.2016.06.022

Bremer, S., \& Glavovic, B. (2013). Exploring the science-policy interface for integrated coastal management in New Zealand. Ocean \& Coastal Management, 84, 107-118. https://doi.org/10.1016/j.ocecoaman.2013.08.008

Brown, C. J., Saunders, M. I., Possingham, H. P., \& Richardson, A. J. (2014). Interactions between global and local stressors of ecosystems determine management effectiveness in cumulative impact mapping. Diversity and Distributions, 20(5), 538-546. https://doi.org/10.1111/ddi.12159

Collobert, R., \& Bengio, S. (2001). Svmtorch: Support vector machines for large-scale regression problems. Journal of Machine Learning Research, 1(2), 143-160. https:// doi.org/10.1162/15324430152733142

Costanza, R., Arge, Groot, R. D., Farberk, S., \& Belt, M. V. D. (1997). The value of the world's ecosystem services and natural capital. Nature, 387(15), 253-260. https:// doi.org/10.1016/S0921-8009(98)00020-2

Crain, C. M., Kroeker, K., \& Halpern, B. S. (2008). Interactive and cumulative effects of multiple human stressors in marine systems. Ecology Letters, 11(12), 1304-1315. https://doi.org/10.1111/j.1461-0248.2008.01253.x

Darling, E. S., \& Isabelle, M. C. (2008). Quantifying the evidence for ecological synergies. Ecology Letters, 11(12), 1278-1286. https://doi.org/10.1111/j.14610248.2008.01243.x

Deter, J., Lozupone, X., Inacio, A., Boissery, P., \& Holon, F. (2017). Boat anchoring pressure on coastal seabed: Quantification and bias estimation using AIS data. Marine Pollution Bulletin, 123, 175-181. https://doi.org/10.1016/j. marpolbul.2017.08.065

Eide, M. S., Yvind, E., Brett, P. O., Ervik, J. L., \& Røang, K. (2007). Intelligent ship traffic monitoring for oil spill prevention: Risk based decision support building on AIS. Marine Pollution Bulletin, 54(2), 145-148. https://doi.org/10.1016/j. marpolbul.2006.11.004

Engle, \& Carole, R. (2016). Sustainable growth of aquaculture: The need for research to evaluate the impacts of regulatory frameworks. Journal of the World Aquaculture Society, 47(4), 461-463. https://doi.org/10.1111/jwas.12340

Fang, X., Zou, J., Wu, Y., Zhang, Y., Zhao, Y., \& Zhang, H. (2021). Evaluation of the sustainable development of an island "Blue Economy": A case study of Hainan, China. Sustainable Cities and Society, 66, Article 102662. https://doi.org/10.1016/j. scs.2020.102662

Fiorini, M., Capata, A., \& Bloisi, D. D. (2016). AIS data visualization for maritime spatial planning (MSP). International Journal of E Navigation \& Maritime Economy, 5(Dec. 2016), 45-60. https://doi.org/10.1016/j.enavi.2016.12.004 
Francour, P., Ganteaume, A., \& Poulain, M. (1999). Effects of boat anchoring in Posidonia oceanica seagrass beds in the Port-Cros National Park (north-western Mediterranean Sea). Aquatic Conservation: Marine and Freshwater Ecosystems, 9(4), 391-400. https://doi.org/10.1002/(SICI)1099-0755(199907/08)9:43.0.CO;2-8

Giakoumi, S., Brown, C. J., Katsanevakis, S., Saunders, M. I., \& Possingham, H. P. (2015) Using threat maps for cost-effective prioritization of actions to conserve coastal habitats. Marine Policy, 61, 95-102. https://doi.org/10.1016/j.marpol.2015.07.004

Graham, E. F., Rebecca, L. F., Linda, M. F., \& Lianna, J. L. (2015). Episodic disturbance from boat anchoring is a major contributor to, but does not alter the trajectory of long-term coral reef decline. PloS One, 10, Article e0144498. https://doi.org/ 10.1371/journal.pone.0144498

Guo, W., Zhang, S., \& Wu, G. (2019). Quantitative oil spill risk from offshore fields in the Bohai Sea, China. Science of The Total Environment, 688, 494-504. https://doi.org/ 10.1016/j.scitotenv.2019.06.226

Hendriks, I. E., Tenan, S., Tavecchia, G., Marbà, N., Jordà, G., Deudero, S., álvarez, E., \& Duarte, C. M. (2013). Boat anchoring impacts coastal populations of the pen shell, the largest bivalve in the Mediterranean. Biological Conservation, 160(1), 105-113. https://doi.org/10.1016/j.biocon.2013.01.012

Holon, F., Boissery, P., Guilbert, A., Freschet, E., \& Deter, J. (2015). The impact of 85 years of coastal development on shallow seagrass beds (Posidonia oceanica L. (Delile)) in South Eastern France: A slow but steady loss without recovery. Estuarine Coastal \& Shelf Science, 165(Nov.5), 204-212. https://doi.org/10.1016/j. ecss.2015.05.017

IMO (International Maritime Organization). (2004). International convention for the control and management of ships ballast water and sediments. B-3.

IMO (International Maritime Organization). (2007). International regulation for the preventing rollision at sea. Annex 1-3.

Jasmi, M. F. A., \& Fernando, Y. (2018). Drivers of maritime green supply chain management. Sustainable Cities and Society, 43, 366-383. https://doi.org/10.1016/j. scs.2018.09.001

Johansson, L., Jalkanen, J. P., \& Kukkonen, J. (2017). Global assessment of shipping emissions in 2015 on a high spatial and temporal resolution. Atmospheric Environment, 167, 403-415. https://doi.org/10.1016/j.atmosenv.2017.08.042

Kim, K. I., \& Lee, K. M. (2020). Convolutional neural network-based gear type identification from automatic identification system trajectory data. Applied Sciences, 10(11), 4010. https://doi.org/10.3390/app10114010

La Manna, G., Donno, Y., Sarà, G., \& Ceccherelli, G. (2015). The detrimental consequences for seagrass of ineffective marine park management related to boat anchoring. Marine Pollution Bulletin, 90(1-2), 160-166. https://doi.org/10.1016/j. marpolbul.2014.11.001

Lester, S. E., White, C., Mayall, K., \& Walter, R. K. (2016). Environmental and economic implications of alternative cruise ship pathways in Bermuda. Ocean \& Coastal Management, 132(Nov), 70-79. https://doi.org/10.1016/j.ocecoaman.2016.08.015

Liu, B., Wu, X., Liu, X., \& Gong, M. (2021). Assessment of ecological stress caused by maritime vessels based on a comprehensive model using AIS data: Case study of the Bohai Sea, China. Ecological Indicators, 126(1), Article 107592. https://doi.org/ 10.1016/j.ecolind.2021.107592

Liu, J., Shi, G., \& Zhu, K. (2019). Vessel trajectory prediction model based on AIS sensor data and adaptive chaos differential evolution support vector regression (ACDESVR). Applied Sciences, 9(15), 2983. https://doi.org/10.3390/app9152983

Liu, Z., Wu, Z., \& Zheng, Z. (2019). A novel framework for regional collision risk identification based on AIS data. Applied Ocean Research, 89, 261-272. https://doi. org/10.1016/j.apor.2019.05.020

Mandal, S., Nagarajan, V., \& Sha, O. P. (2018). Navigational safety and traffic pattern analysis using AIS data on the western coast of India. Current Science, 114(12), 2473-2481. https://doi.org/10.18520/cs/v114/i12/2473-2481

Manna, G. L., Donno, Y., Sarà, G., \& Ceccherelli, G. (2015). The detrimental consequences for seagrass of ineffective marine park management related to boat anchoring. Marine Pollution Bulletin, 90(1-2), 160-166. https://doi.org/10.1016/j. marpolbul.2014.11.001
Mazzarella, F., Vespe, M., Alessandrini, A., Tarchi, D., Aulicino, G., \& Vollero, A. (2017). A novel anomaly detection approach to identify intentional AIS on-off switching. Expert Systems with Applications, 78, 110-123. https://doi.org/10.1016/j. eswa.2017.02.011

Mccauley, D. J., Woods, P., Sullivan, B., Bergman, B., Jablonicky, C., Roan, A., Hirshfield, M., Boerder, K., \& Worm, B. (2016). Ending hide and seek at sea. Science, 351, 1148-1150. https://doi.org/10.1126/science.aad5686

Milazzo, M., Badalamenti, F., Ceccherelli, G., \& Chemello, R. (2004). Boat anchoring on Posidonia oceanica beds in a marine protected area (Italy, western Mediterranean): Effect of anchor types in different anchoring stages. Journal of Experimental Marine Biology \& Ecology, 299(1), 51-62. https://doi.org/10.1016/j.jembe.2003.09.003

Milojevic-Dupont, N., \& Creutzig, F. (2021). Machine learning for geographically differentiated climate change mitigation in urban areas. Sustainable Cities and Society, 64, Article 102526. https://doi.org/10.1016/j.scs.2020.102526

MOT (Ministry of Transport of the People's Republic of China). (2014). Design code of general layout for sea ports (JTS165-013). Beijing: China Communications Press.

MOT (Ministry of Transport of the People's Republic of China). (2017). Technical guidelines on environmental risk assessment of oil spills at waters (JT T 1143-2017). Annex C.

Natale, F., Gibin, M., Alessandrini, A., Vespe, M., Paulrud, A., \& Tserpes, G. (2015). Mapping fishing effort through AIS data. PloS One, 10(6), Article e0130746. https:// doi.org/10.1371/journal.pone.0130746

Piet, G. J., Quirijns, F. J., Robinson, L., \& Greenstreet, S. P. R. (2006). Potential pressure indicators for fishing, and their data requirements. ICES Journal of Marine Science, 64 (1), 110-121. https://doi.org/10.1093/icesjms/fsl006

Robards, M., Silber, G., Adams, J., Arroyo, J., Lorenzini, D., Schwehr, K., \& Amos, J. (2016). Conservation science and policy applications of the marine vessel Automatic Identification System (AIS)—A review. Bulletin of Marine Science, 92(29), 75-103. https://doi.org/10.5343/bms.2015.1034

Rogers, C. S., \& Garrison, V. H. (2001). Ten years after the crime: Lasting effects of damage from a cruise ship anchor on a coral reef in St. John, U.S. Virgin Islands. Bulletin of Marine Science, 69(2), 793-803. https://doi.org/10.1515/BOT.2001.057

Russo, T., Parisi, A., \& Cataudella, S. (2013). Spatial indicators of fishing pressure: Preliminary analyses and possible developments. Ecological Indicators, 26(Mar), 141-153. https://doi.org/10.1016/j.ecolind.2012.11.002

Scanes, C. G. (2018). Human activity and habitat loss: Destruction, fragmentation, and degradation - science direct. Animals and Human Society, 451-482. https://doi.org/ 10.1016/B978-0-12-805247-1.00026-5.

Shafiee, M. E., Barker, Z., \& Rasekh, A. (2017). Enhancing water system models by integrating big data. Sustainable Cities and Society, 37, 485-491. https://doi.org/ 10.1016/j.scs.2017.11.042

Venturini, S., Massa, F., Castellano, M., Costa, S., Lavarello, I., Olivari, E., \& Povero, P. (2016). Recreational boating in Ligurian marine protected areas (Italy): A quantitative evaluation for a sustainable management. Environmental Management, 57(1), 163-175. https://doi.org/10.1007/s00267-015-0593-y

Vespe, M., Gibin, M., Alfredo, A., Natale, F., Mazzarella, F., \& Osio, G. C. (2016). Mapping EU fishing activities using ship tracking data. Journal of Maps, 12, 520-525. https://doi.org/10.1080/17445647.2016.1195299

Wang, Y., Liu, X., Yu, X., \& Zheng, X. (2018). Assessing response capabilities for responding to ship-related oil spills in the Chinese Bohai Sea. International Journal of Disaster Risk Reduction. , Article S2212420918302668. https://doi.org/10.1016/j. ijdrr.2018.02.040

Willsteed, E. A., Birchenough, S. N. R., Gill, A. B., \& Jude, S. (2018). Structuring cumulative effects assessments to support regional and local marine management and planning obligations. Marine Policy, 98(Dec), 23-32. https://doi.org/10.1016/j. marpol.2018.09.006

Zou, Y., Shen, C., \& Xi, X. (2012). Numerical simulations on the motions of anchored capesize ships. Journal of Navigation, 65(1), 145-158. https://doi.org/10.1017/ S0373463311000580 